\title{
Las relaciones culturales, el otro camino. Cuba y la España franquista, 1948-1952*
}

\author{
Cultural relations: An alternative path forward for Cuba \\ and Franco's Spain, 1948-1952
}

\author{
Katia Figueredo Cabrera \\ ORCID iD: http://orcid.org/0000-0003-2157-5359 \\ Universidad de Salamanca
}

El presente trabajo analiza el papel de las relaciones culturales entre la España de Franco y la Cuba de Carlos Prío Socarrás. Sobre todo, en aquellos años inmediatos al término de la II Guerra Mundial cuando la dictadura franquista, convaleciente aún de la Guerra Civil y aislada del escenario internacional, no tuvo más opciones que abandonar sus ínfulas de hegemonía imperial, de madre venerada, y pasar a una nueva fase de colaboración amistosa y de cooperación permanente con la otra orilla del Atlántico. Esta ocasión fue aprovechada además para legitimar la legalidad política del régimen frente al boicot diplomático, y para exportar, de paso, el modelo cultural del nuevo Estado español, ungido de españolismo, tradición y fe.

Palabras Claves: Cuba; España franquista; Relaciones Culturales; La «Misión Poética»; Jaime Balmes; Los Reyes Católicos; I Bienal Hispanoamericana de Arte.

This paper analyzes the role of cultural relations between the administration of Cuban President Carlos Prío Socarrás and Francisco Franco's Spain. Following the end of World War II, Franco's dictatorship was recovering from the civil war, while isolated from the international community; the regime had no choice but to abandon pretenses of imperial hegemony, of "revered mother", and move to a new phase of friendly collaboration and permanent cooperation with its former colonies across the Atlantic. Moreover, the regime used this moment to legitimize its political legality, against diplomatic boycott, and to export the cultural model of the new Spanish State, that included: españolismo, tradition and faith.

Keywords: Cuban; Franco's Spain; Cultural Relations; The Poetic Mission; Jaime Balmes; The Catholic Monarchs; I Hispano-American Art Biennial.

Copyright: (C) 2020 CSIC. Este es un artículo de acceso abierto distribuido bajo los términos de la licencia de uso y distribución Creative Commons Reconocimiento 4.0 Internacional (CC BY 4.0).

* Este artículo se enmarca en el proyecto "Las asociaciones en la emigración exterior española: del mutualismo a las comunidades transnacionales y virtuales" y se encuentra cofinanciado por el Fondo Social Europeo. 


\section{Introducción}

El 12 de octubre de 1955, Alfredo Sánchez Bella, el entonces director del Instituto de Cultura Hispánica (ICH), en un extenso discurso pronunciado en ocasión del Día de la Hispanidad señalaba lo siguiente: «España no puede ser concebida ni entendida sin Hispanoamérica y su cultura sin el conjunto de formas culturales que alientan por tierras americanas, al sur de los Estados Unidos del Norte». ${ }^{1}$ Esta idea, repetida en varios momentos de su dilatada presidencia al frente del $\mathrm{ICH}$, coincidía ahora con un nuevo período para el país: el del final del aislamiento internacional y el del ingreso de España como miembro pleno en las Naciones Unidas. Sin embargo, para llegar hasta aquí, el gobierno de Madrid había tenido que recorrer un largo y angustioso camino que había comenzado en 1945 cuando, tras la derrota del Eje, la aislada y repudiada dictadura se vio obligada a replantearse sus vínculos con América en un sentido diferente al que había caracterizado su primera etapa (1939-1945).

Eufóricos por el triunfo en la Guerra Civil, los vencedores estimaron que había llegado la hora de retomar la unidad del mundo hispánico y, con ella, el alma católica y misionera de la España eterna. Con cierto optimismo, pusieron el acento en la idea de crear allí una «cultura de salvación» para volver a ocupar el puesto que por derecho le correspondía. Sin mucho tiempo que perder, en noviembre de 1940 quedó creado el Consejo de la Hispanidad $(\mathrm{CH})$, el organismo encargado de resucitar la historia imperial, legada por los Reyes Católicos, y de devolverle al país sus días de glorias. No obstante, muy pronto la canción se quedó en la letra. Los objetivos del $\mathrm{CH}$ tropezaron con el hostil escenario en la región, custodiado con celo por los Estados Unidos y por la imagen germanófila de su primer presidente, Ramón Serrano Suñer, conocido popularmente como «el cuñadísimo».

A medida que la guerra comenzó a desbordar los límites de su primitivo emplazamiento y agitar todos los océanos, Franklin Delano Rooselvet reforzó la vigilancia de su patio trasero, el cual no estaba dispuesto a compartir. En pie de alerta, neutralizó la propaganda franquista con una enérgica campaña antiespañola de descrédito que presentó al Consejo como un instrumento de acción para la propagación de las doctrinas totalitarias y a la Hispanidad como el producto a exportar, primeramente, bajo el manto de una reconquista espiritual y, luego, de una reconquista material cuando la situación

1 Sánchez Bella, 1955. 
internacional lo permitiera. En esencia, se alimentó la idea de que el $\mathrm{CH}$ perseguía como único fin minar los fundamentos de la unión panamericana y fortalecer, en su lugar, los de la quintacolumna nazi-fascista-falangista con los conocidos cantos de sirena del idioma, la raza y la religión. ${ }^{2}$

$\mathrm{Al}$ fracaso del Consejo contribuyeron además otros factores como la carencia de recursos económicos del régimen español y lo desacertado de su política exterior, movida, al menos durante los dos primeros años de la guerra, por el convencimiento pleno de Francisco Franco en la victoria del Eje. A la postre, como bien afirma Rosa María Pardo Sanz, el CH no fue más que «una especie de fantasma ruidoso al que nadie tuvo ocasión de ver actuar en América y todo ensayo propagandístico fue tan absurdo como contraproducente ante el clima "democrático" que respiraba el hemisferio occidental». ${ }^{3}$ De modo que, tras la fallida experiencia del Consejo, la aislada dictadura no tuvo más opciones que reconocer su fallo y reinventarse, nuevamente, por la vía de la diplomacia cultural sobre todo a partir de 1943. Ahora se acercaría a América en un tono de fraternidad, y no de prepotencia colonialista, para tratar de iniciar allí un diálogo espiritual que permitiera volver a conectar las dos orillas. Pues la cultura, como bien planteaba el reconocido filósofo español Eugenio D’Ors, era una atmósfera que hacía posible toda forma superior de convivencia.

Con la pretensión de borrar la imagen filofascista de su primera etapa, al finalizar la II Guerra Mundial, el franquismo decidió sustituir el CH por el Instituto de Cultura Hispánica (ICH) y apostar por el ímpetu unificador de las ideas a través del intercambio cultural. Como sujeto activo de esta nueva diplomacia cultural, el nuevo centro se dio a la tarea de crear una extensa red de filiales hispánicas por todo el continente americano que, sobre la marcha y bajo las atentas miradas de Madrid, tratarían de mitigar la influencia de los Estados Unidos, la URSS y el exilio republicano español en la región. También serían utilizadas para revertir, con su labor y por medio de sus interlocutores, toda la propaganda antifascista y antifranquista generada entre 1939 y 1945, para capitalizar adhesiones en contra de las «injustas» condenas impuestas a España por la ONU y para que la dictadura franquista volviera a conectar con aquellos sectores sociales y políticos hispanoamericanos que durante el conflicto civil habían ayudado al bando nacional, pero que después del comienzo de la II Guerra Mundial se habían replegado por el temor de ser acusados de fascistas.

2 Chase, 1943.

3 Pardo Sanz, 1995, 259. 
Ahora bien, el período seleccionado para este trabajo no ha sido al azar. El mismo coincide con la creación en 1948 del Instituto Cultural Cubano-Español (ICCE), filial del ICH, y con la etapa de gobierno en la isla de Carlos Prío Socarrás que, en materia de política exterior, trató en sus inicios de estrechar relaciones con todos los gobiernos de la región, especialmente, con aquellos dominados por las fuerzas democráticas. Sin embargo, la dependencia económica y la cercanía geográfica de la isla a los Estados Unidos, le impediría mantenerse al margen de los efectos inmediatos de la Guerra Fría y de las orientaciones directas de su buen vecino del norte. De hecho, como protagonista del naciente mundo bipolar, Prío no pudo evitar caer, de inmediato, en su órbita geopolítica y entregarse por entero a la cruzada contra el comunismo, considerado por él como el problema más grave para toda la nación en su primer mensaje al Congreso.

Sin embargo, de cara a Europa, básicamente hacia España, el nuevo jefe del poder ejecutivo no estuvo dispuesto a abandonar la diplomacia dual mantenida entre Cuba y las dos Españas desde los años de la Guerra Civil. ${ }^{4}$ Esta ambivalencia diplomática le permitió, desde luego, al ICCE fomentar un nuevo marco de entendimiento cultural, generar un particular espacio de influencia asociativa y desarrollar lealtades trasnacionales en maridaje con los intereses históricos e ideo-políticos de ambos países. Es más, a través del centro hispano-cubano, el régimen franquista logró exportar a «la siempre fiel» los símbolos, imágenes e iconos culturales del tradicionalismo español. También consiguió implementar prácticas movilizadoras y conmemorativas (Día de la Hispanidad, Fiesta Nacional de España...), recuperar a muchos personajes de su pasado histórico, como los Reyes Católicos y Jaime Balmes, y enviar a La Habana a un grupo de selectos «embajadores de la cultura hispana» para quienes «Hispanoamérica no era solo el recuerdo de un pasado glorioso, sino la posibilidad de un futuro». 5

4 La diplomacia dual practicada por el gobierno de La Habana con las dos Españas comenzó a ser habitual a los pocos meses de iniciada la Guerra Civil. El primero de los presidentes cubanos en ejecutarla fue Federico Laredo Bru, quien durante los tres años del conflicto mantuvo el reconocimiento al gobierno del Frente Popular, pero a partir de 1937 comenzó a acercarse a la España nacional. Con el ascenso a la presidencia de Fulgencio Batista en 1940 pocos cambios se suscitaron al respecto. Salvo el reconocimiento oficial a la España franquista y los primeros pasos a favor de la consolidación de las relaciones económicas, Bastita continuó con el mismo coqueteo ambiguo, aunque su alineación a las estrategias defensivas de los Estados Unidos y su declarado carácter democrático y antifascista evidenció, por momentos, una cierta simpatía hacia la «España peregrina». De 1944 a 1948, la presidencia de Ramón Grau San Martín estuvo matizada por la misma ambivalencia política. No obstante, en sus primeros arranques, la balanza llegó a inclinarse hacia la otra España, estando Cuba a las puertas de una ruptura con Madrid.

5 Pérez Vejo, 2013, 1052. 
En el caso de España, el marco cronológico coincide con la elección de dos figuras clave al frente de la reconducción de la política exterior del régimen, sometido, según sus principales portavoces, a una nueva tormenta internacional de injurias, amenazas y calumnias. Hablamos, fundamentalmente, de Alberto Martín Artajo, ministro de Asuntos Exteriores, y de su amigo personal Joaquín Ruiz-Giménez, presidente del ICH. En el primero recayó la tarea «de enarbolar la bandera del catolicismo como seña de identidad; simbología y política mucho más digeribles que la tan vitoreada España del brazo en alto y de la camisa azul». ${ }^{6}$ En tanto a Ruiz-Giménez le fue confiada la misión de reconquistar a través de la cruz - y no de la espada - el antiguo imperio espiritual, bajo el pretexto de mantener unidos a todos los hermanos de sangre frente a un mundo que, corroído por el oleaje materialista, caminaba con pasos agigantados hacia la destrucción de la sociedad, la familia y la religión. Aquello suponía capitalizar las corrientes de simpatías hispanófilas en el Nuevo Mundo «desde las necesarias premisas de la acción cultural hasta la colaboración técnica con los regímenes más afines de Hispanoamérica, toda vez que el modelo español pretendía plasmarse como expresión materializada de una política tradicionalista de carácter funcional». ${ }^{7}$ En otras palabras, urgía salvar y hacer grande nuevamente a España, rescatar con premura sus tradiciones y retomar la obra civilizadora del imperio espiritual en aquellas veinte naciones hijas.

En este sentido, es pertinente resaltar que, a pesar de la importancia coyuntural y estratégica de América Latina como uno de los principales enclaves de legitimación de la aislada dictadura franquista al término de la II Guerra Mundial, en la actualidad el tema carece de un examen sistemático en las dos orillas del Atlántico. Desde la perspectiva española, el foco de atención se ha centrado principalmente en el papel de la diplomacia cultural franquista de cara a Hispanoamérica ${ }^{8}$ y en las diversas estrategias de acercamiento programadas por el ICH (concesión de becas y premios para estudiantes, invitaciones cursadas a intelectuales de países americanos para viajar a España, envío de profesores y conferenciantes españoles a América, fomento de cursos, conferencias y seminarios, celebración de congresos internacionales, etc.). En concreto, los temas tratados, según apunta Rosa María Pardo Sanz, han sido «la ideología y el mundo intelectual de los dirigentes del ICH hasta 1953, en especial la figura de Sánchez Bella y su

6 Moreno Cantano, 2011, 178.

7 Cañellas Mas, 2011, 14.

8 Delgado Gómez-Escalonilla, 2003, 1994a, 1994b, 1993a, 1993b, 1992 y 1988. 
proyecto de difusión de una visión tradicionalista del catolicismo, opuesta al individualismo liberal, que justificaba el modelo corporativo y autoritario franquista». En cambio, resalta esta misma autora, «se ha investigado muy poco el impacto de estas iniciativas en Iberoamérica...». ${ }^{9}$

Al lado de esta realidad, cabría agregar que en los últimos años el impacto de la política cultural española en los grupos hispanistas (profranquistas en la mayor parte de las ocasiones), a través de la creación de Institutos de Cultura Hispánica locales, ha despertado un interés investigativo en la otra orilla, especialmente en México y Argentina. ${ }^{10}$ No obstante, aunque algo se ha avanzado al respecto, todavía el abandono de estos temas sigue siendo visible. Examinemos entonces, desde este prisma, algunos de los mecanismos implementados desde Madrid para echar a andar su maquinaria legitimadora al otro lado del Atlántico y cómo respondió a ellos «la siempre fiel isla de Cuba» y, de manera particular, el ICCE.

\section{A la sombra de la cruz}

Como ha quedado planteado en las primeras páginas, el volver los ojos a América no fue una pretensión vacua y mucho menos antojadiza del gobierno de Madrid. Más que nada porque a partir de 1945 el carácter instrumental de la nueva diplomacia franquista, encuadrada ahora dentro la más pura ortodoxia católica, se asentó en la idea de salvar la continuidad de España en América aprovechando el puente de unión y los puntos de convergencia tendidos por el Atlántico. En realidad, el mundo de la Hispanidad, sembrado y extendido durante la época imperial, se ofrecía como uno de los pocos puertos seguros para legitimar, por un lado, al repudiado régimen y albergar, por otro, la carga de la cultura occidental y cristiana que las primeras naves de los conquistadores habían llevado en su seno.

Como parte de la elaborada coreografía del despertar glorioso de la tradición española, durante los primeros años del aislamiento internacional, la dictadura franquista se encargó de enviar a la mayor de las Antillas a un grupo de «intelectuales misioneros» con el objetivo de combatir por medio de la palabra los temidos fantasmas del jefe de Estado español: la masonería, el liberalismo, el marxismo, el ateísmo, el protestantismo, el racionalismo, el materialismo y el comunismo. Para la clase política del régimen

9 Pardo Sanz, 2016, 138.

10 Para ampliar el estado actual de estos estudios, véase el citado artículo de Pardo Sanz, 2016. 
y, por supuesto, para el propio Franco, la civilización occidental asistía a una crisis general del humanismo en sus dos dimensiones: la temporal y la parcial; o sea, la de la razón y la de la voluntad desarrollada de la jerarquía del Ser. Este proceso de disgregación iniciado con el Renacimiento, continuado por la Reforma protestante y desarrollado por el espíritu reaccionario del Positivismo, había dejado al hombre sin respuesta. De ahí su machacada insistencia en el retorno a las esencias cristianas, a ese catolicismo integral de espíritu creador, rector del mundo moderno y guía de los valores permanentes del ser y de la cultura, sobre el cual debía descansar el futuro de toda la humanidad para alcanzar la verdadera justicia.

En consonancia con este anacrónico rescate del pasado, purgado de las excrecencias antiespañolas, el catolicismo volvió a tomar las riendas de la Hispanidad para levantar, junto con sus hijas de América, un nuevo imperio espiritual donde ya no se pondría más el sol. Por lo tanto, serían las tesis de Marcelino Menéndez Pelayo, Juan Donoso Cortés, Jaime Balmes Urpía, Juan Vázquez de Mella, Julián Juderías, Víctor Pradera y Ramiro de Maeztu las que encontrarían continuidad en los escritos de los nuevos exponentes del régimen como Manuel García Morente, José Pemartín, Rafael Calvo Serer, José María Pemán, Rafael Gil Serrano, Manuel Fraga Iribarne, Ernesto Giménez Caballero... Y las que, a su vez, sostendrían los misioneros de ese mundo civil y eclesiástico que, a los acordes de la variopinta gama interpretativa del nacionalcatolicismo y del pensamiento anti y contrarrevolucionario español, cruzarían el Atlántico para fundamentar la grandeza de la «nueva España», actualizar las bases de su cultura tradicional y medir, de paso, el estado de opinión en aquellas lejanas tierras.

Con estas ansias de regreso a las glorias pretéritas, la América perdida, y no la Europa de Carlos V, fue la que pasó a formar parte de «la extensión transatlántica de una España que volvía a ocupar su nicho ideológico "natural" de guardiana de las esencias de la tradición y el conservadurismo». ${ }^{11}$ No obstante, en realidad, el largo viaje perseguía un objetivo mucho más concreto: tratar de debilitar el cerco internacional a través de la creación de lobbies profranquistas para luchar desde diversos frentes contra la «gran injusticia» orquestada en los salones de la ONU. Esta tarea implicaba establecer vínculos de contacto con los católicos y políticos conservadores e intentar limar, en la medida de lo posible, las asperezas latentes dentro de la fragmentada comunidad de emigrantes españoles, asentados en Hispanoamérica.

11 Pérez Vejo, 2013, 1065. 
Sobre la marcha, se intentaría también atraer a aquellos sectores vinculados, directa o indirectamente, con el comercio español y, más que nada, a esa otra minoría de intelectuales inasequible al desaliento, como la llamaba Rafael Gil Serrano; ${ }^{12}$ la encargada, entre otras funciones, de recibir y agasajar a toda la pléyade de «intelectuales católicos», provenientes de España que, en palabras de Mario Martín Gijón, no eran «sino ideólogos del régimen y publicistas de la jerarquía católica española, que tenían muy poco que ver con intelectuales católicos como Jacques Maritain, Emmanuel Mounier o François Mauriac, pensadores independientes respecto al poder y críticos con las actitudes políticas de la jerarquía y a los que lógicamente odiaban visceralmente». ${ }^{13}$

Ahora bien, en el caso de Cuba, sus receptores más visibles estuvieron a la sombra de la variopinta gama de integrantes que formaron parte, sobre todo, de la nómina del ICCE. Hablamos, básicamente, de abogados, políticos, profesores del Colegio de Belén y de la Universidad Católica de Santo Tomás de Villanueva, así como de periodistas, columnistas y colaboradores del Diario de la Marina, El País, Mañana, Información y de las revistas Cuba. Raíz de España en América y Cultura Hispánica. ${ }^{14}$ Otras tribunas de legitimación al franquismo constituyeron, sin duda, las diversas asociaciones religiosas como los Caballeros de Colón, las Damas Isabelinas, la Asociación de Católicas Cubanas y la Casa Cultural de Católicas, además de señalados centros regionales de la colonia española, cuyas juntas directivas estaban controladas por las élites más conservadoras. ${ }^{15}$

12 Gil Serrano, 1947.

13 Martín Gijón, 2011, 259-260.

14 En la primera junta directiva del ICCE figuró el jurista José Agustín Martínez Viademonte (presidente); el abogado y político José Manuel Cortina García (primer vicepresidente); el destacado hispanista José María Chacón y Calvo (segundo vicepresidente); el abogado Manuel Pérez Picot (secretario); el periodista gallego Antonio Docampo de la Fuente (vicesecretario); los comerciantes españoles Enrique Gancedo Toca (tesorero) y José Justo Martínez (vicetesorero), el abogado Manuel Dorta Duque (interventor) y el funcionario Félix Chediak Ahuayda (viceinterventor). Los expedientes del centro, conservados en el Archivo Nacional de Cuba, ofrecen muy poca información sobre las actividades de esta asociación. Otro de los problemas radica en la ausencia de una revista que, si bien llegó a proyectarse como idea, en la práctica nunca se concretó. De ahí que para la reconstrucción de la historia del ICCE haya sido preciso revisar de manera minuciosa el Diario de la Marina, su mayor tribuna de divulgación. Para ampliar información sobre el ICCE, véase Figueredo Cabrera, 2018.

15 Según el padre cubano Gustavo Amigó, el prestigio y la influencia de la Iglesia Católica en Cuba era incuestionable y esto se debía, en los últimos tiempos, a la formación de las vocaciones sacerdotales y religiosas impulsadas por el cardenal Manuel Arteaga Betancourt. En cifras, concretaba la idea Amigó: «Cuba posee actualmente, según el Censo oficial de 1943 (publicado en 1945), unos 4.778.583 habitantes. Si exceptuamos a unos 50.000 protestantes de diversas sectas, a unos 100.000 incrédulos abiertos (es cifra apreciativa, como la siguiente) y concedemos un margen prudencial (más 
Delimitadas entonces las estrategias a seguir y los grupos interesados por «las grandes esencias de la Hispanidad católica», en septiembre de 1948 llegó a La Habana el religioso y catedrático Juan Tusquets Tarrats, uno de los personajes del franquismo más obsesionados por la masonería en España y a quien Franco había designado, en 1937, para trabajar en el Servicio de Prensa Nacional de Burgos con la tarea de detectar cualquier influencia masónica. En el momento de su arribo a la isla, Tusquets Tarrats ocupaba el cargo de director diocesano de Instrucción Religiosa, función que compartía con la de profesor de Criteriología Religiosa en la Universidad de Barcelona y con la de catedrático de Pedagogía en el Seminario Conciliar de esta misma ciudad.

Como parte de su estancia en la capital cubana, el presbítero catalán ofreció un cursillo de metodología catequística en la Congregación Mariana de la Anunciata y dictó una conferencia en los salones del ICCE sobre el origen y evolución de las religiones. De regreso a España, Tusquets aceptó publicar en la revista española Orientación Catequística un artículo titulado «Impresiones de un viaje a Cuba». En las primeras líneas del escrito mostró complacencia por la lucha constante del cardenal Manuel Arteaga Betancourt contra la masonería y su entrega a la formación levítica de un clero nativo desde las aulas del Seminario del Buen Pastor. Según sus estadísticas, el $20 \%$ de los 500 sacerdotes diocesanos y regulares (uno por cada 9.000 habitantes) había nacido en Cuba. A partir de estas premisas alabó, además, el trabajo consciente de las agrupaciones católicas juveniles, la elevada marca pedagógica del Colegio de Belén, «quizás el mejor del mundo», y el creciente ascenso del movimiento hispanista como hecho indiscutible y real del ICH. No menos optimistas fueron sus palabras de elogio para la incipiente corriente cultural que, desde el interior del ICCE, comenzaba a gestarse en la mayor de las Antillas, así como sus esperanzas de impulsar por medio de este centro grandes iniciativas a favor de la educación religiosa para ayudar a contrarrestar el laicismo en la enseñanza oficial cubana, refrendado desde 1940 en el artículo 51 de su Carta Magna.

Apenas unos pocos meses después de la visita de Tusquets, el centro cultural recibió a otras tres personalidades españolas más: al superior general de la Orden de los Dominicos, Manuel Suárez Fernández; al escritor segoviano Francisco de Cossío, director del Museo de San Gregorio de

amplio que estrecho) de 10.000 individuos para otras religiones, podríamos afirmar que todo el resto, más de cuatro y medio millones en números redondos, es católico más o menos instruido y practicante». Amigó, 1951, 177. 
Valladolid y del Museo de Escultura de Madrid, y al obispo claretiano de Barbastro, Alfredo Tabera Araoz. Procedente de Santo Domingo, Suárez Fernández llegó en compañía de su secretario, el padre José Manuel de Aguilar, cuñado de Joaquín Ruiz-Giménez, y del también padre Basilio Jiménez. A este destacado asturiano, el primer religioso español en haber alcanzado el título de abogado en el Supremo Tribunal de la Sagrada Rota Romana, lo unían a Cuba fuertes vínculos familiares y de gratitud. Su padre había vivido en la isla a finales del siglo XIX y durante los primeros meses de la Guerra Civil española, él y el portero de la comunidad del Convento del Olivar habían sido los dos únicos sobrevivientes de los excesos iniciales del conflicto, gracias al asilo brindado por la Embajada de Cuba en Madrid. Sin más intenciones que un viaje rutinario de inspección para dejar organizada en el país una campaña de vocación religiosa, el destacado jurista aceptó la invitación de José Agustín Martínez Viademonte, presidente del ICCE, para pronunciar una conferencia en el centro cultural sobre el origen y desarrollo del derecho internacional.

Como hombre de letras, las dos charlas de Francisco de Cossío, una dictada en la Facultad de Letras de la Universidad de La Habana y la otra en el ICCE, versaron acerca de la evolución del arte hispano y sus distintas manifestaciones. Siguiendo con la misma tónica iniciada por Juan Tusquets, de regreso a España después de un viaje de tres meses por Centroamérica y las Antillas, De Cossío se aventuró a publicar también sus impresiones sobre Cuba en la revista Cuadernos Hispanoamericanos bajo el título «Hijos de españoles». Como buen observador, llegó a la conclusión de que los esfuerzos de cuatro siglos de dominación colonial habían dejado una huella profunda en aquellas tierras y que la independencia estaba demasiado próxima para que un español se sintiera ajeno en ellas. De ahí su llamada de alerta sobre el peligro de los Estados Unidos en la región y a no perder de vista la isla porque, quizás, este era el territorio más español de América y el de mayores posibilidades migratorias. De hecho, sus intenciones no pasaron desapercibidas cuando sugirió utilizar el recién creado ICCE para fortalecer el intercambio cultural a través de una comunicación mutua y más estrecha.

Ahora bien, de estos tres visitantes, la conferencia de Alfredo Tabera Araoz, «El momento católico en España», fue de entre las aquí citadas la que más colorido le imprimió a la apología triunfalista del régimen franquista en materia religiosa. Y razones existían para ello. Barbastro había sido la diócesis de toda España con más sacerdotes sacrificados durante el 
conflicto civil (90\% de todo su clero). Se calcula que, durante el transcurso de la guerra, 830 personas fueron fusiladas debido a su condición católica, religiosa o sacerdotal, aunque el hecho más remarcado por la Iglesia al término del conflicto sería precisamente el asesinato de 51 claretianos en el temprano mes de agosto de $1936 .{ }^{16}$

Tomando como ejemplo este suceso y auxiliándose, en parte, de la información publicada por el régimen hasta ese momento, Tabera Araoz centró su plática en los estragos materiales y humanos ocasionados a la institución eclesiástica española durante los sangrientos años de la contienda fratricida. ${ }^{17}$ También aprovechó su intervención para resaltar la injustificada destrucción y quema de iglesias y seminarios y, subrayar, de manera particular, el asesinato de «veinte mil sacerdotes a manos de los rojos». ${ }^{18}$ Cifra que, como es sabido al día de hoy, no es la manejada por la historiografía española, pues existe un consenso en aceptar el homicidio aproximado de unos 7.000 eclesiásticos del clero regular y secular. ${ }^{19}$ En su afán por mejorar la dañada imagen de la dictadura y apaciguar, en buena medida, las constantes campañas anticatólicas promovidas por una parte del exilio republicano, el obispo español no dudó tampoco en mostrar su satisfacción por el nuevo período de paz y sintetizar los notables éxitos alcanzados en cuestiones de la fe al término de la llamada Cruzada.

A esta lista de visitantes cabría agregar otros nombres como el del periodista, novelista y biógrafo gallego Luciano de Taxonera Vivanco y el de los padres jesuitas Miguel Batllori, José Ignacio Martín Artajo y Joaquín Azpiazu. Mención aparte dentro de este grupo merecen para terminar otros dos conferenciantes españoles. Nos referimos al médico y religioso bilbaíno Pedro Arrupe y al literato orensano Eugenio Montes Domínguez: El primero por la amplia cobertura radiofónica, periodística y hasta televisiva que su visita originó a la isla y el segundo por la cordial acogida en las sociedades gallegas de la capital cubana.

Arrupe llegó a La Habana a mediados de 1951, rodeado de una triste y reciente tragedia que de inmediato impactó a la opinión pública nacional. Había sido uno de los sobrevivientes de la explosión de la bomba atómica

16 Al respecto, véase Codinachs i Verdaguer, 1997; Aparicio Rodríguez, 1992.

17 Desde el mismo 1 de abril de 1939, la dictadura franquista se dio a la tarea de dar a conocer su propia «verdad» en dos libros muy publicitados: La gran víctima. La Iglesia española mártir de la revolución roja (1940), de Aniceto de Castro Albarrán, y el titulado Causa General. La dominación roja en España (1943).

18 Friguls, 1949, 10.

19 Montero Moreno, 1961 
en Hiroshima, ciudad donde trabajaba como misionero jesuita desde 1938. De modo que, llevado por este afán humanitario y apostólico, se aventuró a realizar una larga travesía por todo el continente americano a fin de recaudar fondos para el auxilio a las víctimas del desastre y el orfanatorio creado en la devastada localidad nipona. También lo movía un deseo personal por dar a conocer la situación del Japón al otro lado del Atlántico y sus experiencias vividas aquella dantesca mañana del 6 de agosto de 1945. Impulsado por esta labor, Pedro Arrupe pronunció varias charlas en la capital cubana, dos de ellas en el ICCE, y en Santiago de Cuba.

A diferencia del padre Arrupe, La Habana no era del todo desconocida para Eugenio Montes Domínguez. Su primera visita había tenido lugar en septiembre de 1938 cuando, procedente de América del Sur y en calidad de consejero de Francisco Franco, realizó una corta parada en la capital cubana junto a su colega Samuel Ros Pardo, delegado de Prensa de la Falange Española Tradicionalista y de las Juntas de Ofensiva Nacional Sindicalista (FET y de las JONS), para cumplimentar parte de la misión propagandística que lo había llevado a recorrer varias repúblicas del continente. A mitad de 1951, Montes Domínguez volvió a hacer escala en la isla después de trece años de ausencia. De paso para España, tras haber representado a su país en las fiestas centenarias de la Universidad de San Marcos de Lima y haber pronunciado conferencias en Colombia y Panamá, accedió a la propuesta del encargado de Negocios español, Germán Baraibar Usandizaga, de dictar una charla en el ICCE sobre la poetisa gallega Rosalía de Castro. A finales de año regresaría nuevamente a La Habana, pero en esta ocasión como convidado especial de la Asociación Iniciadora y Protectora de la Real Academia Gallega para participar en los actos por el centenario de Manuel Curros Enríquez.

Ahora bien, mientras los portavoces del franquismo se recreaban en los salones del ICCE, Carlos Prío Socarrás complacía a medias a los republicanos españoles y a los grupos antifranquistas al aprobar una ayuda mensual de 1.500 dólares para el gobierno del exilio, ${ }^{20}$ y al consentir la visita de Félix Gordón Ordás, el último embajador de la República Española en Cuba, y del filósofo catalán José Ferrater Mora. Incluso, su hermano, Antonio Prío Socarrás, ministro de Hacienda, fue uno de los que recibió personalmente al líder socialista Indalecio Prieto, a quien se le llegó a insinuar que el presidente cubano estaba dispuesto a cubrir holgadamente

20 Domingo Cuadriello, 2009. 
sus gastos si aceptaba quedarse definitivamente en el país. ${ }^{21}$ Durante su mandato, Prío permitió además las labores del Círculo Republicano Español y de otras agrupaciones de menor importancia, no así las de la Casa de la Cultura, hostigada con frecuencia por su abierto carácter comunista. Esta visible tolerancia venía a ratificar, una vez más, que el príiato había optado, al igual que sus antecesores, por la cómoda posición de nadar entre las turbulentas aguas de las dos Españas, irremediablemente opuestas, en espera de que fueran ellas mismas las que encontraran el justo medio para el entendimiento.

\section{La «Misión Poética»: una afirmación de confianza}

Otro de los intentos del gobierno de Madrid por acercarse a «la siempre fiel» fue, sin duda, el envío a La Habana, a finales de diciembre de 1949, de la conocida «Misión Poética», patrocinada por la Dirección General de Relaciones Culturales y el ICH. ${ }^{22}$ Integraban la comitiva cuatro reconocidos literatos del franquismo: Luis Rosales Camacho, Leopoldo Panero, Antonio Zubiaurre y Agustín de Foxá, que se les uniría en Nueva York aprovechando la primera escala del largo periplo que los llevaría de visita por diversas naciones del continente. Todo apunta a que esta nueva embajada cultural, la primera que llegaba a la isla, respondió a un interés muy particular del ministro de Asuntos Exteriores de España por exportar uno de los rostros más apacibles de la aislada dictadura, después del gran triunfo moral obtenido ese año en los salones de la ONU gracias al apoyo recibido de varios países latinoamericanos. ${ }^{23}$ Sin embargo, más atento en preservar y fortalecer la imagen del régimen al otro lado del Atlántico, Alberto Martín Artajo desestimó, de entrada, la realidad política de algunas de aquellas repúblicas, al menos las ubicadas en la región del Caribe.

21 Centro Documental de la Memoria Histórica, Incorporados, 63, 11/11294. 2007.

22 Un primer acercamiento sobre la «Misión Poética» fue publicado en Figueredo Cabrera,

23 A finales de 1949, el franquismo asumió como un triunfo moral el apoyo recibido por un grupo de países latinoamericanos a la moción presentada por Brasil en los primeros meses del citado año. En líneas generales, Brasil sugería que se le otorgara a todos los estados miembros de las Naciones Unidas el derecho a establecer relaciones diplomáticas normales con el régimen de Franco. Aunque esta proposición no alcanzó la mayoría requerida, el gobierno de Madrid valoró la votación como una gran victoria. Puesto que veinte naciones, de las seis pronunciadas en 1946 (todas ellas latinoamericanas), habían cambiado de parecer respecto a continuar prorrogando el boicot internacional, y antes de que finalizara el año diez más habían anunciado el envío de sus embajadores a España. 
En el caso de Puerto Rico, la noticia de la visita de los poetas hispanos exacerbó el clima de hostilidad reinante hacia la España franquista. En carta fechada el 14 de diciembre de 1949 desde la capital boricua, el cónsul español Pablo de Ubarri ponía sobre aviso al nuevo presidente del ICH, Alfredo Sánchez Bella, sobre la embarazosa situación creada allí y este, a su vez, hacía extensiva la preocupación a Rosales Camacho con instrucciones precisas para él y sus otros tres acompañantes: «[...] se está tratando de daros acceso a la Universidad de Puerto Rico, generalmente hostil hasta ahora hacia España, pero gracias a una presión hábil y diplomática del grupo católico, es factible conseguirlo haciendo la aclaración de que los vuestros serán recitales absolutamente culturales y sin sabor político alguno». La nota continuaba diciendo: «Ubarri insiste, por tanto, en que tengáis exquisito cuidado en no tocar en lo más mínimo nada que pueda considerarse como propaganda política». ${ }^{24}$

Por otro lado, las primeras horas de la llegada a La Habana de la «Misión Poética» transcurrieron en la más absoluta tranquilidad. El 21 de diciembre fueron recibidos en un ambiente íntimo en la casa de sus amigos el periodista Pablo Álvarez de Caña y su esposa, la poetisa Dulce María Loynaz. Al día siguiente, la acogida se trasladó a los salones de la Sociedad Económica de Amigos del País, pero este acto social, el primero de bienvenida, organizado por el Ateneo de La Habana, estuvo muy lejos del apacible y amistoso entorno de la noche anterior. La velada literaria comenzó con un discurso del destacado hispanista José María Chacón y Calvo y fue seguido de un recital de poesía en la voz de sus invitados, cuando de repente un grupo de jóvenes irrumpió de manera violenta en el local lanzando «en dirección a la mesa una lluvia de tomates y huevos podridos». De inmediato se personó en el lugar el cuerpo de policía, alertado desde el día anterior por el propio Chacón y Calvo, «debido a las amenazas telefónicas anónimas que este había recibido». Los agentes del orden lograron detener a cuatro jóvenes que fueron «conducidos a la Sexta Estación de Policía y de allí al Vivac; pero al día siguiente salieron en libertad. Acusados del delito de desorden público por motivos políticos, fueron juzgados el 14 de abril de 1950 y resultaron absueltos». ${ }^{25}$

24 Cartas y tarjetas de visita, con breves textos escritos, de Alfredo Sánchez Bella a Luis Rosales Camacho, 1949, Archivo Histórico Nacional de España (AHN), Diversos-Luis Rosales, 89 , n. 31 .

25 Domingo Cuadriello, 2009, 91. 
Controlados los «revoltosos», el 27 de diciembre la embajada cultural se dio cita en la Academia Nacional de Artes y Letras. A solicitud de su presidente, Miguel Ángel Carbonell Rivero, las palabras de salutación estuvieron a cargo de Dulce María Loynaz que, sin ánimo de racionalizar elogios, presentó a los «ilustres» convidados como hombres de honor. Luego, y atendiendo a un motivo personal, enlazó directamente su intervención, a riesgo de herir sensibilidades según palabras textuales, con la visita realizada por Federico García Lorca a la isla a inicios de los años treinta y, de manera particular, a su residencia en el aristocrático barrio del Vedado. La misma que recibía ahora a estos nuevos poetas. Con detalle recordaba la reconocida poetisa:

Era el año de 1930, año en que muchos de los que hoy gritan no habían nacido y otros ya nacidos y crecidos apenas se preocupaban de su existencia, cuando Federico García Lorca estuvo en Cuba. Y puedo decirles que ese año largo de su estancia en ella, lo pasó el poeta en mi casa. Excepto dormir, allí comió, allí rió, allí lloró, allí hizo versos [...]. Cuando partió —y para siempre — dejó a mi hermana en prenda de amistad el original de su drama Yerma, escrito de su mano [...]. A mi hermano Carlos dedicó su drama inédito El Público, a Enrique algunas de sus más bellas cartas que él gustaba de ilustrar con extraños dibujos de monigote [...]. De modo que tengo razones para creer que en Cuba nadie puede hablar de García Lorca más alto que yo. ${ }^{26}$

¿Qué razones impulsaron a Dulce María Loynaz a evocar aquella tarde a una de las figuras señeras de las letras hispanas? La remembranza tenía por objetivo minimizar ante los presentes y en los principales medios de comunicación nacional la dañada imagen de Luis Rosales Camacho, que desde inicios de diciembre circulaba en algunos rotativos de la isla como Noticias de Hoy: «Luis Rosales, el cabecilla de la misión, fue el traidor que consiguió engañar la buena fe de García Lorca para que se ocultara en su residencia de Granada, de donde lo sacó a los pocos días para entregarlo al pelotón de la Guardia Civil que asesinó por la espalda al gran poeta español». ${ }^{27}$ Siguiendo con esta misma tónica, aunque más prudente en sus acusaciones, el semanario antifranquista Bohemia se limitó a poner solo en tela de juicio una imputación no probada hasta ese momento:

Granadino como Lorca, [Luis Rosales Camacho] jugó un destacado papel, no del todo aclarado todavía, en la prisión y muerte del autor de «Bodas de Sangre». Al surgir

26 Discurso de Dulce María Loynaz, 1949, AHN, Diversos-Luis Rosales, 89, n. 31.

27 Delgado, Emilio, «Los asesinos del poeta García Lorca viajan a Puerto Rico, Cuba y América del Sur», Noticias de Hoy, 290, La Habana, 9 de diciembre de 1949, 4. 


\section{KATIA FIGUEREDO CABRERA}

la rebelión militar en España, Federico García Lorca se había refugiado en casa del poeta Rosales, huyendo de los criminales de la Falange que lo buscaban para darle muerte. ¿Salió Federico por deseo propio de casa de Rosales o fueron allí a buscarle sus asesinos? Rosales ha dicho, en más de una ocasión, que Lorca abandonó su casa en contra de las recomendaciones que él le había hecho [...]. Aún aceptadas estas excusas de Rosales nadie ha logrado expresar todavía cómo después no denunció a las autoridades franquistas, con las cuales se llevaba perfectamente, a los asesinos de su amigo Lorca. ${ }^{28}$

En este duelo de tintas y de denuncias apasionadas, el Diario de la Marina no escatimó esfuerzos para desmentir cualquier implicación de Rosales Camacho en la supuesta delación de Lorca y arremeter, de paso, contra los marxistas cubanos: «La falsa noticia inexistente dio pretexto para que la prensa comunista hiciera gala, una vez más, de su perfecta ignorancia, aun en el terreno periodístico, pues es cosa ya averiguada la completa inocencia de Rosales en la muerte del malogrado García Lorca». ${ }^{29}$

En realidad, sobraban motivos para que la estancia de los poetas españoles en La Habana ocupara por aquellos días la atención de las principales columnas de la prensa escrita. Con encendidos editoriales, los detractores del franquismo no tardaron en calificar a la «Misión Poética» como un esfuerzo más de la «siniestra Falange» para expandir la propaganda hispanista dentro de los círculos culturales y acrecentar el número de adeptos para sus «planes colonizadores». Sin quedarse a la zaga, Bohemia publicó además una síntesis biográfica de cada uno de los «genuinos representantes de esa España de cuartel que administra Franco a base de bayonetas y tarjetas de racionamiento». ${ }^{30}$ Mientras que la Federación Estudiantil Universitaria (FEU), apoyada por el Partido Socialista Popular, hizo llegar por escrito al Ministro de Estado una solicitud de expulsión inmediata del país para aquellos «extranjeros indeseables». ${ }^{31}$

Conforme avanzó su estadía en la capital cubana, el tono de las ofensas e incriminaciones fueron subiendo de temperatura. Se llegó al extremo, incluso, de acusar a Luis Rosales Camacho de la delación del poeta Miguel Hernández, muerto de tuberculosis en la prisión de Alicante cuatro años

28 «Embajada poética de Falange», Bohemia, 52, La Habana, 25 de diciembre de 1949, 81.

29 «Se llevó a cabo una brillante velada literaria en los salones de la Sociedad Económica Amigos del País», Diario de la Marina, 304, La Habana, 24 de diciembre de 1949, 32.

30 «Viajeros. Embajada poética de la Falange», Bohemia, 52, La Habana, 25 de diciembre de 1949,81

31 «Luis Rosales, jefe de la misión falangista fue quien entregó a Federico García Lorca», Noticias de Hoy, 306, La Habana, 28 de diciembre de 1949, 1. 
después del triunfo de los nacionales. También se hizo habitual el empleo de motes peyorativos para ridiculizar a los visitantes. Cítese como muestra algunos de ellos aparecidos en las páginas del rotativo comunista Noticias de Hoy y de la revista Nosotros. España Republicana: «poetillos falangistas disfrazados de poetas», «binomios de ilustres desconocidos», «pandillas de sinvergüenzas», «traidores», «asesinos» $\mathrm{y}$ «heraldos del generalísimo», entre otros.

De esta oleada de imputaciones pocos lograron escapar. La misma se hizo extensiva, con similar hosquedad, a las instituciones e intelectuales vinculados con los huéspedes españoles. José María Chacón y Calvo, por ejemplo, fue incriminado por un falso y erróneo pasado. Nadie ignora, comentaba un encendido artículo de Noticias de Hoy, «la filiación falangista del voluminoso ex director de Cultura, quien no faltó a ninguno de los actos de Falange Española y a los Te Deum en memoria del fascista José Antonio Primo de Rivera». ${ }^{32}$ No sería ocioso detenerse unos segundos para recordar que durante los años de la contienda fratricida en España, el VI Conde de Casa de Bayona nunca se vinculó con la derecha hispano-cubana ni participó en las actividades organizadas por la FET y de las JONS de Cuba. ${ }^{33}$ Basta solamente leer entre líneas su Diario íntimo de la Revolución Española para constatar el profundo dolor que, desde el 18 de julio de 1936, embargó a este reconocido intelectual cubano por los excesos de la guerra, así como su labor humanitaria desarrollada a favor de los asilados en la Embajada de Cuba en Madrid en aquellos primeros meses donde la vida no tenía valor.

Análogos improperios recibió José Agustín Martínez Viademonte, coronado, al igual que los poetas franquistas, con un rosario de motes ofensivos como «falangista hispano-guerrillero», «valedor del franquismo en la isla», «decrépito falangista», «representante del régimen criminal y carcelero de la nueva España» y «cabeza directriz de la caverna criolla» (se refiere al ICCE). Tampoco faltaron aquellos que lo acusaban de poner al centro cultural a disposición de los planes imperialistas del dictador español. A esta campaña de virulentas diatribas se sumó el comunista cubano Juan Marinello Vidaurreta que, sin medias tintas, arremetió contra Dulce María Loynaz y un grupo de redactores del Diario de la Marina:

32 «Repudio a una misión franquista», Noticias de Hoy, 301, La Habana, 22 de diciembre de 1949,6

33 Véase Figueredo Cabrera, 2014. 
Que recibiera y festejara a la embajada literaria franquista el grupo del Diario de la Marina nos pareció cosa natural y obligada. Si los Baquero, Mañach, Ichaso y Chacón y Calvo son la tropa de choque de un diario falangista, debían, en cumplimiento de un deber elemental, acoger a sus congéneres de allende [...]. La acción militante de la señora Loynaz, que con ir a la España de Franco estaba definida en el peor sentido, era del mismo modo esperada. ${ }^{34}$

Sea como fueren los hechos, lo cierto es que de este clima de antipatía verbal no quedó mucho más que el testimonio y la voluntad de unas ilusiones frustradas. Puesto que la «Misión Poética» permaneció en la capital cubana hasta finales de año, recibiendo con entera normalidad todo tipo de atenciones y agasajos. El 28 de diciembre de 1949, por ejemplo, la junta directiva del ICCE le ofreció un homenaje de despedida. En un ambiente de ostensible cordialidad, el presidente del Instituto soslayó, en sus palabras de apertura, las jornadas de repudio organizadas en La Habana por los grupos antifranquistas y resaltó, en su lugar, la importancia de la visita de los cuatro poetas españoles para la consolidación de la hermandad hispano-cubana. Con orgullo manifiesto, José Agustín Martínez agregó que el ICCE no pretendía redescubrir la cultura de la «Madre Patria» ni despertar el amor a España, dos cimientos de profundas raíces en los habitantes de la isla. Únicamente, intentaba restablecer una nueva y poderosa corriente de savia española para enriquecer, vivificar y nutrir la sangre criolla con el nuevo quehacer intelectual que ahora surgía en la península. Esta era, en su opinión, la mejor manera de demostrar el cariño hacia esa «madre generosa y tierna» que nos había dado el ser y que gracias a su grandeza espiritual había logrado superar los rencores y resentimientos de épocas pasadas.

El resumen de la actividad estuvo a cargo de Dulce María Loynaz que, un poco más sosegada, pasó también por alto las provocaciones de los días anteriores. La poetisa se limitó a expresar solamente la deuda de gratitud de todos los cubanos con España y a evocar como testimonio de dicha amistad algunos fragmentos de los versos sencillos de José Martí. Sin embargo, muy lejos estaban de avizorar los allí presentes que la tertulia sería interrumpida, otra vez y de manera sorpresiva, por una manifestación estudiantil que, de forma violenta, penetró en el local para dar un giro inesperado a la noche. Los gritos de ¡Mueran los asesinos de García Lorca! y ¡Muera Franco! se escucharon en los salones del Automóvil y Aéreo Club

34 Marinello, Juan, «Con Franco o con García Lorca», Nosotros. España Republicana, 158, La Habana, 7 de enero de 1950, 1. 
de Cuba. Rápidamente, la policía ocupó el lugar y dispersó a los «revoltosos», poniendo fin a la velada de modo imprevisto.

De Cuba, la «Misión Poética» continuó su viaje por otros países del continente americano, sin que la FEU viera cumplidos sus sueños de expulsar a los «extranjeros indeseables» en justo agravio a los sentimientos antifranquistas del pueblo cubano. En Bogotá, los intelectuales españoles fueron recibidos por el ministro de España José María Alfaro, en Ciudad Trujillo por su homólogo Manuel Aznar y en Nicaragua por el presidente Anastasio Somoza. Sin embargo, en Venezuela no lograron escapar de unos actos de protesta de mayor hostilidad y violencia que los presenciados en La Habana. La escena quedó preparada el mismo día de su presentación en el Hogar Americano, cuando el rotativo marxista El Nacional, de Caracas, publicó la siguiente información: «Darán hoy un recital cuatro poetas españoles. Son los mismos abucheados hace poco en La Habana. Llevan dos días de silenciosa permanencia en Venezuela. Se hospedan en el Hotel Waldorf. Uno de ellos está indicado como el delator de García Lorca. Esta tarde, a las seis, darán un recital en el Hogar Americano». ${ }^{35}$ Durante su presentación, los visitantes fueron presa de insultos, agravios y de proyectiles de vegetales lanzados hacia ellos. El mobiliario fue destruido en su totalidad y la policía detuvo a trece personas, todas de filiación comunista.

De regreso a España y en una entrevista concedida al $A B C$, Panero, Rosales Camacho y Zubiaurre acusaron a los «camaradas de la hoz y el martillo» de todo el ambiente de animosidad fomentado contra la «embajada cultural de buena voluntad» en Cuba, Venezuela y Costa Rica. Así y todo, no tuvieron a menos el reconocer su satisfacción por el trato recibido en la prensa: «A veces fuimos honrados con elogios hiperbólicos y en otros el denuesto rozó también la hipérbole y, por último, en algunas ocasiones fuimos simplemente material informativo, según el matiz político de los periódicos que se ocuparon de nosotros». ${ }^{36}$ No obstante, en realidad, los mayores elogios en España fueron para Dulce María Loynaz, catalogada por la revista madrileña Clavileño como la mejor anfitriona de la «Misión Poética» en la mayor de las Antillas: «Los comunistas cubanos acusaron al poeta Luis Rosales de ser el causante de la muerte de García Lorca, cosa incierta totalmente, y Dulce María tomó la defensa contra la calumnia. Presentó a

35 Citado en Sagrera, 2009, 75.

36 «Entrevista $\mathrm{ABC}$ a los poetas que nos visitaron», Diario de la Marina, 63, La Habana, 16 de marzo de 1950, 17. 
los poeta españoles, abordando de cara la cuestión». ${ }^{37}$ Sin olvidar los infortunios de aquel viaje, años más tarde Agustín de Foxá reconocería, en carta a su madre, lo prematuro y arriesgado de aquella misión y con el fino humor que lo caracterizaba añadía algunas observaciones interesantes:

Te haría gracia en mi carta anterior ver las ovaciones frenéticas que me dieron en el Ateneo de La Habana [hace alusión a 1952], el mismo sitio donde hace dos años ¡nos recibieron con tomates y huevos podridos! Este cambio se debe, en parte, a nuestro tacto y política, pero, sobre todo, a ese bendito paralelo 38 de Corea, al cual deberían alzar en el Pardo una estatua, pues ha convertido (en opinión mundial) a nuestro gobierno de fascista en demócrata $[\ldots] .^{38}$

\section{La mise en scène. Todos los «dioses» vuelven a su trono}

No es posible comprender la celebración en Cuba del I Centenario de la muerte de Jaime Balmes Urpía y del V Centenario del nacimiento de los Reyes Católicos, si no se tiene en cuenta la obra de trasmisión cultural promovida por la dictadura franquista hacia las repúblicas de la América hispana, sobre todo después de 1945 . De manera paralela a su proceso de institucionalización, el Estado español se convirtió en un ente exportador de imágenes y mitos a través de los cuales buscaba suscitar un consenso de naturaleza emocional y transmitir el significado simbólico de sus normas y valores para disipar, por un lado, la leyenda negra fortalecida durante estos años y salvar, por otro, la conciencia de destino común perdida por la dispersión decimonónica.

A partir de estas premisas, la imagen de una España eterna, misionera, católica y universal cruzó el Atlántico y ancló allí su cuarta carabela lista para combatir a la otra España, según Rafael Gil Serrano, la enemiga irreconciliable, la siempre aliada del mal; la España esclava de las fuerzas internacionales masónico-marxistas; la propulsora de los desastres internacionales; la España disgregadora, traicionera, la juramentada con los enemigos seculares de Dios y la Iglesia. En otras palabras, la España negra, la del horror. ${ }^{39}$ Con el retorno al universalismo de tipo católico y tridentino, que había nutrido al país de reservas morales y era la clave de

37 «De La Habana ha venido un barco con Dulce María Loynaz», Clavileño, 38, Madrid, 15 de diciembre de 1951, 15.

38 Citado en Gracia, 2006, 142.

39 Gil Serrano, 1947. 
su grandeza y misión histórica, la diplomacia cultural franquista volvió a revivir a las figuras más descollantes de su antiguo parnaso y con ellas el sentido profundo de la historia española, entendido como la consustancialidad entre la patria (lo nacional) y la religión. Servir a Dios era servir a España; servir a España era servir a Dios. Renunciar al pasado y a la tradición era dejar a la nación sin esencia. Era el hueco, la tumba y la sepultura de España. ${ }^{40}$

En esencia, hubo un acuerdo generalizado de proyectar la España del pasado como el futuro inmediato para la regeneración católica de la civilización occidental y como el único camino para el regreso al Imperio español, o sea, al Imperio de la Hispanidad. Atendiendo a esta voluntad, no resultó casual que un manto de silencio cubriera la memoria de los vencidos y sus «malos recuerdos». Las herejías, la Ilustración, el pensamiento liberal de los siglos XVIII y XIX, el anti-tradicionalismo de las Cortes de Cádiz, el movimiento profano o anti-español como el marxismo o el producido por los intelectuales de la II República, etc., fueron borrados de la historia o deformada su interpretación. Igual suerte corrieron las obras de Francisco Giner de los Ríos, Manuel Azaña, Antonio Machado, Rafael Alberti, Federico García Lorca y Miguel Hernández, cuyos nombres desaparecieron de los papeles escritos. Se llegó a prohibir la reedición de sus textos y tanto la censura como los nuevos inquisidores no tuvieron reparos en purgar cuidadosamente todas las bibliotecas en donde figurasen sus recuerdos. Estos fueron sustituidos por los conocidos best sellers del pensamiento católico-tradicionalista a fin de justificar a Franco, ante Dios y ante la historia, como el continuador de aquellos siglos de esplendor.

Con la creación en La Habana del ICCE y la aparición de un nuevo escenario cultural, la diplomacia franquista dejó allanado el camino para su mise en scène. Es más, desde su propio arranque, no escatimó en poner sus escasos recursos económicos en función de toda la fiebre de conmemoraciones desde «la versión católica conservadora, más atenta a los indisolubles vínculos de la nación con la defensa de la fe religiosa y de la monarquía». ${ }^{41}$ Un fenómeno que, con total acierto, Javier Moreno Luzón ha dado en llamar centenariomanía o conmemoracionitis.

El primer turno correspondió a Jaime Balmes Urpía en 1949 con ocasión del primer centenario de su muerte, aunque en Cuba estas actividades

40 García Morente, 1947.

41 Moreno Luzón, 2009, 131. 
rememorativas estuvieron muy lejos de alcanzar el impacto logrado en España. ${ }^{42}$ El recién estrenado ICCE se sumó con entusiasmo a la cruzada intelectual promovida por el ICH, pero solo consiguió coordinar la conferencia «El pensamiento filosófico de Balmes a cien años de distancia», pronunciada por Miguel Batllori, de visita por aquellos días en la capital cubana, la tierra de su madre. También, y en un primer intento por incentivar los estudios sobre la vida y obra del filósofo y sociólogo vicense, el centro cultural convocó a un concurso nacional cuyas bases aparecieron publicadas en las páginas del Diario de la Marina. Al tibio colorido de la efeméride balmesiana contribuyó además el sacerdote segoviano Jerónimo García Gallegos, exiliado en la isla desde inicios de la década de 1940, con otras dos charlas: una dictada en el Ateneo de La Habana y la segunda en la Academia Nacional de Artes y Letras.

Continuando con el orden cronológico de celebraciones, el segundo turno correspondió a los Reyes Católicos. No obstante, la propuesta de algunos de festejar un centenario genuinamente matrimonial como síntesis de la conocida frase de la época del «tanto monta, monta tanto...» quedó en el papel, ya que Isabel logró acaparar todo el protagonismo en ambas riberas del Atlántico. En el caso de la mayor de las Antillas, la reina fue sobredimensionada con florecidas adjetivaciones cuasi místicas en los trabajos periodísticos que, a partir de 1951, comenzaron a publicarse, sobre todo, en el Diario de la Marina, mientras un manto de silencio ensombrecía la vida de su compañero. Para el periodista cubano Gastón Baquero Díaz, por ejemplo, Isabel no era la esposa de Fernando, sino al revés. Fernando era el esposo de Isabel. La soberana simbolizaba a la española perfecta y él, al clásico europeo interesado solo por sus posesiones en Italia.

Sin embargo, detrás de esta invitación al diálogo y a la meditación con la Historia, propuesta por el reconocido periodista cubano, para los miembros del ICCE y de las instituciones culturales y religiosas que de inmediato compartieron el entusiasmo por la gran fiesta espiritual en la isla, la celebración encerraba tres significados de excepcional magnitud. Desde el punto de vista moral, un apoyo al levantamiento del interdicto diplomático contra España. Desde el punto de vista práctico, un toque de atención al lamentable empecinamiento oficial del gobierno cubano por mantener una política de inhibición frente al nombramiento de un embajador

42 Fernández Pousa, 1951. 
en Madrid. ${ }^{43} \mathrm{Y}$, desde el punto de vista histórico, el nacimiento de una mujer única, clarividente, iluminada por la fe, de cualidades excepcionales y símbolo de todo: la reconquista, el descubrimiento de América, la tónica moral de la colonización y la limpieza radical de la nación española. En otras palabras, la encarnación del carácter y las virtudes del nuevo Estado, nacido el 18 de julio de 1936, la Eva cristiana y el modelo inigualable de madre y gobernadora, de mujer y reina. Esta última convicción encajaba perfectamente con las aspiraciones legitimadoras del régimen franquista que, envalentonado por su posible reinserción en la lid internacional, aprovechó el momento para otorgarle a la efeméride una solemnidad inusitada y sacar ventajas de ella. La presentó como el gran acontecimiento de toda la comunidad hispánica, heredera de Fernando e Isabel, y sobredimensionó su impacto haciendo partícipe al continente americano de algunas de sus actividades más relevantes. ${ }^{44}$

A la vista de los ampulosos planes proyectados desde Madrid, el ICCE exteriorizó un entusiasmo muy diferente al presenciado durante los festejos por el centenario de Jaime Balmes. Y los motivos tendríamos que buscarlos, primero, en el compromiso contraído por su director en una de las sesiones plenarias del I Congreso de Cooperación Intelectual (Madrid, 1950); y, segundo, en los contornos especiales que la dictadura le imprimió a la efeméride en todo el mundo de habla hispana. De regreso a la isla, José Agustín Martínez Viademonte se enfrascó en la elaboración de un minucioso plan de ceremonias que venía acariciando desde hacía dos años en las juntas mensuales del centro. La primera reunión tuvo lugar a inicios de marzo de 1951 en los salones de la Embajada de España con la participación de destacadas figuras de la colonia española y del mundo socio-económico, intelectual y eclesiástico de la isla.

Aquella tarde, los presentes acordaron aprovechar la estancia en La Habana del pianista y compositor gaditano José Antonio Cubiles Ramos, profesor del conservatorio de Madrid contratado por la sociedad Pro Arte Musical, para que ofreciera un concierto de música en el local social del instituto. También se aprobó la puesta en circulación de una emisión especial

43 Desde mayo de 1939 hasta abril de 1952, las relaciones diplomáticas entre Cuba y España se mantuvieron a nivel de Encargado de Negocios. Fue necesario esperar hasta un mes después del golpe de Estado propinado por Fulgencio Batista al presidente constitucional Carlos Prío Socarrás para que ambos países acordaran nombrar un embajador en sus respectivas sedes. Sobre este período, véase Figueredo Cabrera, 2016.

44 Para más información acerca de los actos conmemorativos en España y América, véase Homenaje a los reyes fundadores de América, 1953. 
de sellos alegóricos a la fecha, la convocatoria de un concurso periodístico relacionado con la vida y obra de los soberanos españoles y la gratificación con premios en metálico para el mejor guion cinematográfico, crónica, composición poética y obra dramática relacionada con la época. La invitación se hizo extensiva además a todos los centros regionales españoles del país y a los principales colegios religiosos, a los cuales se les exhortó la impartición de clases especiales de historia, dirigidas a resaltar la grandiosa epopeya del descubrimiento. No menos llamativa resultó la lectura de las bases del concurso literario presentado por los Caballeros Católicos y la organización de un programa radiofónico, en cuatro charlas, dedicado a la gran reina de Castilla por la Asociación de Católicas cubana.

Concretado todos los detalles, el 17 de marzo el ICCE dejó inaugurada extraoficialmente la festividad con el concierto de Cubiles Ramos y la apertura de un ciclo de conferencias en su edificio social. Dos meses después, conforme a lo planificado, el Diario de la Marina hizo pública la convocatoria del concurso «España en la conquista y civilización de América» para todos los escritores y periodistas en activo residentes en el territorio nacional. Los trabajos debían hacer alusión, en conjunto o por separado, a la acción religiosa, cultural, jurídica, artística, social, fundacional, económica, etc., de España en el Nuevo Mundo. El primer premio sería gratificado con una estancia de un mes en la «Madre Patria», que incluía pasaje de ida y vuelta en la línea regular de Iberia Habana-Madrid-Habana. Mientras que el segundo sería recompensado con doscientos pesos cubanos y un diploma acreditativo.

Ante este cuadro de realidades prácticas, el 22 de abril de 1951, día del nacimiento de Isabel, quedaron inaugurados de manera oficial, al igual que en España, los festejos por el centenario en la capital cubana. Esa mañana, los pórticos barrocos de la catedral abrieron sus puertas para recibir a una nutrida representación del cuerpo diplomático hispano y latinoamericano, de la Orden de los Caballeros de Colón, las Damas Isabelinas y el ICCE. En ausencia del cardenal Manuel Arteaga Betancourt, por aquellos días en Guatemala, la ceremonia pontifical fue oficiada por el obispo auxiliar de $\mathrm{La}$ Habana, Alfredo Müller, asistido de otros prelados. El panegírico a Isabel estuvo a cargo de Alfredo Llaguno que, en una emotiva oración, destacó las virtudes de la soberana como la redentora de las almas indígenas y la madre común de todos cuantos el destino había puesto en su regazo. En esta misma línea argumental habló el ministro español Germán Baraibar Usandiza, Gastón Baquero Díaz y el profesor universitario Jorge Mañach. 
Como parte de las actividades del programa cultural, la Asociación de Católicas dio inicio ese mismo 22 de abril a un ciclo de cuatro charlas por su programa radiofónico «Actualidad Católica». Por aquellos meses fue noticia también la exposición de fotografía testimonial del África occidental española exhibida en el ICCE por el jurista hispano Fernando F. Suárez Kelly, quien había sido letrado asesor del régimen franquista en esas tierras. Estudioso además de la figura de los monarcas españoles, Suárez Kelly aprovechó su corta estancia en la capital cubana para develar en una de sus dos conferencias datos desconocidos acerca de la vida privada de los Reyes Católicos y, de manera muy particular, aquel relacionado con el lugar de nacimiento de la reina. Una larga controversia histórica que dijo quedar zanjada finalmente con la aparición en la Biblioteca Nacional de Madrid del diario del enigmático doctor de Toledo, médico de Isabel, con la siguiente información: «Nació la sancta reyna, doña Isabel fija del Rey Don Juan II e de la Reyna Isabel, su mujer, en Madrigal, jueves XXII de abril III horas y II tercios de hora después del mediodía, 1451 años». ${ }^{45}$

Como colofón de estas celebraciones, el 12 de octubre de 1951, el centro cultural organizó una misa y un Te Deum en la Catedral de La Habana y, dos meses después, dejó cerrado el programa de actos con la charla de la profesora Hilda Ruiz Castañeda «La música en la corte de Fernando e Isabel». De esta forma se ponía punto final a las actividades del centenario sin generar, como en el caso de la «Misión Poética», críticas periodísticas o jornadas de protestas por los opositores del franquismo en la mayor de las Antillas. En concreto, pocas dudas quedaban al respecto. El éxito organizativo había superado al fracaso, al no ser interpretadas todas estas iniciativas como parte de la política rapaz del dictador español. Incluso, hasta el exaltado y antifranquista semanario Bohemia se sumó al gesto de cordialidad con la publicación de varios artículos dedicados a rememorar la fecha y a enaltecer los aciertos de la reina.

\section{Por los caminos del arte}

Mientras en La Habana se ultimaban los preparativos para la clausura del V Centenario de los Reyes Católicos, el 12 de octubre de 1951, España se hacía eco de dos singulares acontecimientos, presididos por el jefe de

45 «a verdad sobre el nacimiento de la reina Dña. Isabel la Católica», Diario de la Marina, 107, La Habana, 5 de mayo de 1951, 10. 
Estado español. Nos referimos a la apertura del nuevo edificio del ICH en los terrenos de la Ciudad Universitaria y a la inauguración de la I Bienal Hispanoamericana de Arte en el Museo de Arte Moderno de Madrid. En cumplimiento con los acuerdos emanados del I Congreso de Cooperación Intelectual y los resultados obtenidos en el I Salón de Artistas Iberoamericanos (en junio de 1950), este último certamen, organizado por el Instituto Cultural Madrileño, buscaba fomentar, por un lado, el mutuo conocimiento y desarrollo de las artes plásticas producidas en la comunidad de pueblos hispánicos y, por el otro, hacer extensivo su radio de acción a los artistas de Portugal, Brasil, Filipinas y los Estados Unidos que, en calidad de participantes de honor, se les concedió el derecho a disfrutar de los mismos privilegios que los dispuestos para los creadores hispanoamericanos. ${ }^{46}$

No obstante, en la línea de esta alentadora integración comunitaria, no todos los involucrados con el gran acontecimiento, el primero de su tipo en España, albergaron las mismas expectativas. Para la élite de poder, la cita sería la ocasión perfecta de comenzar a consolidar la apertura del país al mundo con el regreso de los embajadores a suelo español. Esto contribuiría a aumentar el prestigio cultural del régimen y, de paso, «aquilatar y prestigiar la ideología de la hispanidad». ${ }^{47}$ Para los más soñadores, en cambio, a España le había llegado la hora de disputarse el centro del arte moderno entre Roma y París, pese a la ausencia de reconocidos pinceles como Joan Miró y Pablo Picasso, quien estrenaría públicamente su actitud de rechazo hacia todo proyecto artístico-cultural promovido por el franquismo desde su exilio en París. Mientras, los interesados y defensores del arte renovador veían con optimismo el advenimiento de una posible evolución del régimen y de su hasta ahora menguada política cultural con el nombramiento de Joaquín Ruiz-Giménez como ministro de Educación, justamente tres meses antes de la inauguración oficial de la Bienal. Como hombre de talante más liberal, el antiguo embajador español ante la Santa Sede entendía que, en la esfera de la creación artística, el Estado debía de huir de la «intromisión totalitaria que [...] esclaviza, haciendo de las obras de la inteligencia y del arte unos serviles instrumentos de la política concreta». ${ }^{48}$ En este sentido, le otorgaba una legítima zona de autonomía como expresión libre del alma individual, en la cual el poder estatal no podía por su propio interés inmiscuirse.

46 Al respecto, véase Llorente Hernández, 1995; Felipe Vivanco, 1952.

47 Cabañas Bravo, 1996, 223.

48 Ruiz-Giménez, 1952, 163. 
Para la selección de las obras españolas, el ICH creó una junta organizadora, presidida por Alfredo Sánchez Bella y altos exponentes de la cultura franquista, y dejó en mano de los gobiernos latinoamericanos la responsabilidad de la elección a través de la convocatoria de exposiciones preliminares. En el caso de Cuba, las bases aparecieron publicadas en el Diario de la Marina en el mes de abril de 1951, y cuatro meses después, conforme a las orientaciones emanadas desde la península, la exhibición preparatoria quedó inaugurada en los salones del ICCE. De los cincuenta artistas inscritos, en su mayoría noveles, cuarenta y siete resultaron escogidos para un total de cincuenta y tres cuadros de pintura, quince trabajos de dibujos y grabados y once esculturas que al mes siguiente fueron embarcados en el vapor Magallanes rumbo a España.

No obstante, la ausencia de firmas reconocidas, algunas por prejuicios políticos y otras por problemas personales, vino a ratificar los pronósticos reservados del jurado durante la muestra. Cuba, a pesar de ser una de las naciones de América Latina con mayor representatividad y de contar con la presencia de Dulce María Loynaz en el comité de calificación, elegido por el ICH, solo logró alzarse con un lauro: el del escultor Rolando López Dirube, gratificado con el Premio Líneas Áreas Iberia de 2.000 pesetas.

Dos años habrían de transcurrir para que los artistas cubanos consiguieran enmendar su actuación en Madrid. La ocasión se mostró propicia en 1953, al ser seleccionada La Habana sede de la II Bienal Hispanoamericana de Arte en medio de una dictadura que había interrumpido, sin miramientos, el proceso democrático en la isla y estrechado aun más sus relaciones con el caudillo español. En concreto sería en «la siempre fiel» donde el franquismo, una vez rehabilitado de su ostracismo diplomático, lograría su segundo espaldarazo artístico a nivel internacional. ${ }^{49}$

\section{Conclusiones}

A modo de conclusión pudiéramos volver sobre algunas ideas que nos parecen interesante subrayar. Primero: Que la decisión del franquismo de supeditar la acción cultural a su política exterior, sobre todo a partir de 1945, respondió, básicamente, a la necesidad de supervivencia del repudiado régimen en Europa y a la búsqueda, por consiguiente, de apoyo y

49 Sobre la II Bienal Hispanoamericana de Arte, véase Figueredo Cabrera, 2015. 
de legitimación internacional al otro lado del Atlántico. Ello explica que la cultura emergiera como elemento integrador, al captar el gobierno de Madrid lo aconsejable de volver a acercarse a su antiguo imperio colonial y comenzar a entender que la Hispanidad, en cuanto ámbito del espíritu, no era aprehensible por si sola. Tenía que corporizarse en su dimensión americana y derivar en una estrategia conciliadora y fraterna.

Segundo: Que, en el caso de Cuba, el nuevo diseño cultural, pensado en los salones del Palacio de Santa Cruz, supo beneficiarse de la diplomacia dual practicada por La Habana para crear un estado de opinión favorable a la «nueva España». Esta ventaja les permitió a los portavoces del franquismo actuar con cierta comodidad entre un selecto grupo de intelectuales y políticos conservadores que, al margen de su posicionamiento ideológico, otorgaban a las relaciones culturales una importancia capital en tanto puente de unión entre el viejo y el nuevo continente. Con cierto agrado, los hispanófilos cubanos advertían la necesidad de una aproximación hacia la «Madre Patria» a través del intercambio recíproco de ideas y de proyectos en el plano de la compresión mutua y desinteresada. Toda vez que, para ellos, la Hispanidad no era un simple vocablo formulista ausente de realidad o sentido. El término encerraba una sustancia real que transcendía más allá de un giro retórico, un coloniaje ideológico o una fórmula original de neocolonialismo. Desde esta matriz interpretativa asumieron gustosamente una parte del amplio recetario de actividades y propuestas diseñadas por el régimen franquista en esa búsqueda constante por el diálogo amistoso entre ambas orillas. Su especial compromiso quedó materializado en la celebración de dos centenarios -el de Jaime Balmes Urpía (1949) y el de los Reyes Católicos (1951) — en su valiosa contribución con la I Bienal Hispanoamericana de Arte (1951) y en la acogida brindada a los «nuevos embajadores» de la cultura hispánica que, provenientes de Madrid, pisaron tierra cubana.

Y tercero: Que, en términos prácticos, fue un acierto de España el poder sumar a este reducido grupo de intelectuales y políticos cubanos a su proyecto cultural para impulsar la nueva ofensiva en el extranjero a medida que la fiebre del antifascismo se fue sustituyendo por la del anticomunismo, su mejor carta de triunfo. Téngase a bien recordar, grosso modo, la influencia en estos espacios de José Manuel Cortina García, primer vicepresidente del ICCE. Como secretario de Estado, durante los años de la Guerra Civil española, Cortina García no solo había manifestado una simpatía muy especial por el bando nacional, sino que a inicios de la década de 1940 consolidó 
su posición al frente del Ministerio de Estado al oponerse a cualquier tentativa dirigida a entorpecer las relaciones diplomáticas entre Cuba y la España franquista. Importante resultó ser además para el prestigio del centro cultural la presencia dentro de su junta directiva del reconocido hispanista y diplomático José María Chacón y Calvo, de los destacados juristas y también políticos José Agustín Martínez Viademonte y Manuel Dorta Duque, y de Enrique Gancedo Toca, comerciante santanderino que años después sería calificado por el periódico $A B C$, de Madrid, como el millonario español más joven de Cuba.

Vistas así las cosas, no parece arriesgado afirmar que Francisco Franco nunca caminó en suelo pantanoso. Siempre estuvo seguro de que en aquella parte del continente podía granjearse el apoyo, por poco que fuera, de un conjunto de interlocutores con capacidad y poder en diversas esferas de la política doméstica en espera de la revocación de las sanciones internacionales. En la práctica, a través de ellos logró acrecentar el menguado prestigio internacional de la dictadura y convertir a «la siempre fiel isla de Cuba» en una de sus bases operativas de la otra orilla.

\section{Referencias bibliográficas}

Amigó, Gustavo, «Cuba», en Pattee, Richard (ed.), El catolicismo contemporáneo en Hispanoamerica, Buenos Aires, Editorial FIDES, 1951.

Aparicio Rodríguez, Ángel, Seminario claretiano mártir. Barbastro 1936, Madrid, Publicaciones Claretianas, 1992.

Cabañas Bravo, Miguel, La política artística del franquismo. El hito de la Bienal Hispano-Americana de Arte, Madrid, RB Servicios Editoriales, 1996.

Cañellas Mas, Antonio, América y la Hispanidad. Historia de un fenómeno cultural, Pamplona, Ediciones Universidad de Navarra, 2011.

Castro Albarrán, Aniceto de, La gran víctima. La Iglesia española mártir de la revolución roja, Salamanca, Talleres Cervantes, 1940.

Causa General. La dominación roja en España, [Madrid], Ministerio de Justicia, 1943.

Codinachs i Verdaguer, Pere, El holocausto claretiano de Barbastro (1930-1936). Los hechos y sus causas, Badalona, Fundación Cristianismo y Testimonio, 1997. 


\section{KATIA FIGUEREDO CABRERA}

Chase, Allan, Falange. El ejército secreto del Eje en América, s. 1., Editorial Caribe, 1943.

Delgado Gómez-Escalonilla, Lorenzo, Diplomacia franquista y política cultural hacia iberoamérica 1939-1953, Madrid, CSIC, 1988.

Delgado Gómez-Escalonilla, Lorenzo, Imperio de papel. Acción Cultural y política exterior durante el franquismo, Madrid, CSIC, 1992.

Delgado Gómez-Escalonilla, Lorenzo, «El recurso al "mundo hispánico": elaboración y trayectoria de una política de sustitución», en Tusell, Javier; Sueiro, Susana; Marín, José María y Casanova, María, El régimen de Franco (1936-1975), Madrid, Universidad Nacional de Educación a Distancia, 1993a, 515-533.

Delgado Gómez-Escalonilla, Lorenzo, «Entre la Hispanidad beligerante y la Comunidad Hispánica de Naciones (1939-1953)», en Pérez Herrero, Pedro y Tabanera, Nuria (coords.), España/América Latina: un siglo de politicas culturales, Madrid, Asociación de Investigación y Especialización sobre Temas Iberoamericanos-AETI/Síntesis/Organización de Estados Iberoamericanos, 1993b, 91-136.

Delgado Gómez-Escalonilla, Lorenzo, «De la regeneración intelectual a la legitimación ideológica: la política cultural de España (1921-1945)», Spagna contemporanea, 6, Alesaandria (Italia), 1994a, 51-71.

Delgado Gómez-Escalonilla, Lorenzo, «El factor cultural en las relaciones internacionales: una aproximación a su análisis histórico», Hispania. Revista Española de Historia, 54, 186, Madrid, 1994b, 257-278.

Delgado Gómez-Escalonilla, Lorenzo, «Libros y revistas para América: política cultural y producción editorial del Instituto de Cultura Hispánica», en La huella editorial del Instituto de Cultura Hispánica, Madrid, Fundación MAPFRE Tavera, 2003, 23-39.

Domingo Cuadriello, Jorge, El exilio republicano español en Cuba, Madrid, Siglo XXI de España Editores, 2009.

Felipe Vivanco, Luis, Primera Bienal Hispano Americana de Arte, Madrid, Afrodisio Aguado, 1952.

Fernández Pousa, Ramón, El primer centenario de Balmes en la prensa española, Madrid, Magisterio Español, 1951.

Figueredo Cabrera, Katia, «Cuba en la estrategia cultural de la España franquista», Pensamiento y Cultura, 10, Colombia, 2007, 191-207.

Figueredo Cabrera, Katia, Cuba y la Guerra Civil española. Mitos y realidades de la derecha hispano-cubana (1936-1942), La Habana, Editorial Universidad de La Habana, 2014.

Figueredo Cabrera, Katia, «La Segunda Bienal Hispanoamericana de Arte», Espacio Laical, 3 y 4, La Habana, 2015, 48-54.

Figueredo Cabrera, Katia, «Francisco Franco y Fulgencio Batista: Complicidad de dos dictadores en el poder (1952-1958)», Tzintzun. Revista de Estudios Históricos, 64, Morelia, 2016, 296-335. 
Figueredo Cabrera, Katia, «Un abrazo cultural entre la Cuba republicana y la España franquista, 1948-1958», Investigaciones Históricas. Época Moderna y Contemporánea, 38, Valladolid, 2018, 451-478.

García Morente, Manuel, Idea de la Hispanidad, Madrid, Espasa Calpe, 1947.

Gil Serrano, Rafael, Nueva visión de la Hispanidad, Madrid, Imprenta Prensa Española, 1947.

Gracia, Jordi, Estado y cultura. El despertar de una conciencia crítica bajo el franquismo, 1940-1962, Barcelona, Anagrama, 2006.

Homenaje a los reyes fundadores de América, Madrid, Ediciones Cultura Hispánica, 1953.

Llorente Hernández, Ángel, Arte e ideología en el franquismo (1936-1951), Madrid, Visor, 1995.

Martín Gijón, Mario, Los (anti) intelectuales de la derecha en España. De Giménez Caballero a Jiménez Losantos, Barcelona, RBA, 2011.

Moreno Cantano, Antonio César, «El Servicio de Prensa Exterior de España en Hispanoamérica durante la Segunda Guerra Mundial», en Cañellas Mas, Antonio, América y la Hispanidad. Historia de un fenómeno cultural, Pamplona, Ediciones Universidad de Navarra, 2011, 153-180.

Moreno Luzón, Javier, «Mitos de la España inmortal. Conmemoraciones y nacionalismo español en el siglo XX», en Forcadell, Carlos; Salomón, Pilar y Sanz, Ismael (eds.), Discursos de España en el siglo XX, Valencia, Universitat de València, 2009, 123-146.

Montero Moreno, Antonio, La persecusión religiosa en España 1936-1939, Madrid, Editorial Católica, 1961.

Pardo Sanz, Rosa María, Con Franco hacia el Imperio. La política exterior española en América Latina, 1939-1945, Madrid, Universidad Nacional de Educación a Distancia, 1995.

Pardo Sanz, Rosa María, «De puentes y comunidades: balance historiográfico sobre las relaciones con América Latina», en Martín de la Guardia, Ricardo; Delgado Gómez-Escalonilla, Lorenzo y Pardo Sanz, Rosa María (eds.), La apertura internacional de España. Entre el franquismo y la democracia, Madrid, Sílex, 2016, 127-166.

Pérez Vejo, Tomás, «España vista desde Hispanoamérica», en Morales Moya, Antonio; Fusi Aizpurúa, Juan Pablo y De Blas Guerrero, Andrés (dirs.), Historia de la nación y del nacionalismo español, Barcelona, Galaxia Gutenberg, 2013, 1048-1069.

Ruiz-Giménez, Joaquín, «Arte y política», Cuadernos Hispanoamericanos, 26, Madrid, febrero, 1952, 162-165.

Sagrera, Luis, Agustín de Foxá. Una aproximación a su vida y obra, Burgos, Editorial DosSoles, 2009.

Sánchez Bella, Alfredo, «En torno a la cultura hispanoamericana», Diario de la Marina, 234, La Habana, 13 de octubre de 1955, 4-A. 